\title{
Papers
}

Explorations into Children's Literature

\section{Charity and Children's Literature}

\section{Kristine Moruzi}

This special issue on charity and children's literature emerges out of my current research on how children are encouraged to see themselves as charitable beings. In this historical project, I examine a range of children's magazines from the nineteenth and early twentieth centuries to analyse which children are inducted into habits of philanthropy while other children are depicted as the recipients of good will and material benefits. This research has shown that children have been understood to have the potential to act as charitable agents for hundreds of years. Yet it also reflects the complex interaction between children and charity in children's literature, where sometimes the charitable children are not only the recipients of charity, but are also inspired to help others as well.

The question of children's ethical responsibility to help others in need is central to the articles in this special issue. Many critics of children's literature concede that 'at least one function of a children's book is to shape the evolving moral character of its readers' (Mills 2014, p. 5). The articles included here examine a range of charitable practices facilitated by different organisations to encourage children to help others. Both Sue Chen and Hugh Morrison explore the missionary culture of the late nineteenth and early twentieth centuries to demonstrate how religious organisations encouraged child readers to support a variety of charitable causes related to missionary activity. Rebecca-Anne Do Rozario and Heather Snell 
approach the question of charity in children's literature using contemporary texts in which the charitable impulse is no longer focused simply on financial contributions. Instead, Do Rozario discusses the ethos of charity in Terry Pratchett's Tiffany Aching novels, and Snell uses two different genres, dystopian literature and 'voluntourism literature' to explore the politics of charity within the neoliberalism of the twenty-first century. These articles indicate the extent to which ideas about children's charity have shifted in the last 150 years in terms of how and why children should either perform or fund works of charity. Yet, importantly, these articles also suggest that encouraging children to think of others continues to be a central concern in literature for children.

Chen examines representations of children and charity in British missionary magazines, fiction, cantatas, and other pamphlets that discuss Chinese missions. She explores how missionary societies encouraged children to contribute to foreign missions through special talks, lantern lectures, bazaars, plays, and magazines. This 'participatory relationship' was encouraged in a multiplicity of print materials published between 1890 and 1939 in which Chinese children were presented in terms of social, political, and economic difference from the British children who were encouraged to help those less fortunate.

In his article, Morrison looks at a related participatory relationship in his exploration of New Zealand children's charity through the lens of the New Zealand Presbyterian Church. This historical examination of children's charity focuses on the children's magazine The Break of Day as the vehicle through which Protestant New Zealand children learned about - and were encouraged to support - the church's annual 'Christmas Present fund'. Between 1909 and 1945, children were involved in a variety of activities that raised thousands of pounds for missions in Asia and the South Pacific. This community of New Zealand children fostered 
denominational and national allegiances while also bringing the child readers into contact with other cultures and communities around the world.

Do Rozario's discussion of the Tiffany Aching novels (The Wee Free Men [2003], A Hat Full of Sky [2004], Wintersmith [2006], I Shall Wear Midnight [2010], and The Shepherd's Crown [2015]) in Terry Pratchett's Discworld series demonstrates how witches such as Tiffany form a crucial part of the community. By drawing on the history of fairy tales about witches and old women, Do Rozario argues that the series of novels depicts traditions of care and preservation as the young heroine matures. She becomes a strong, public-focused witch who performs charitable work because it is necessary and important, even when it may preclude the traditional fairy tale conclusion of romance, fame, or fortune.

In contrast to the expectations of charity and public service that are somewhat implicitly demanded of the witches in the Pratchett novels, Snell examines more explicit charitable work in Neal Shusterman's Unwind series (2007-2015) and Eric Walters' Alexandria series (2008-2010). In the dystopian Unwind novels, those who rescue unwanted teens from the threat of being unwound are celebrated. The voluntourist genre of the Alexandria series also celebrates people who help others in need, often through development work. Both genres are seemingly 'other-regarding', as Snell explains, and encourage readers to adopt a charitable outlook as they mature into adulthood. Yet both series highlight the difficulty of seeing beyond the self as one performs charitable works.

From the nineteenth century to the twenty-first century, these four articles reflect the change material conditions by which children are encouraged to help others. Certainly the children who were targeted in the nineteenth-century missionary and church magazines are very 
different from the implied readers of the twenty-first-century fiction. Those historical children were encouraged to raise money, but not to directly intervene in the lives of others. In contrast, contemporary children are encouraged - and expected - to actively participate in the charitable venture itself. This speaks to the changing nature of childhood and the ways in which society's expectations of children have shifted, while still maintaining a consistent ethos of charity as an ideal for children.

\section{References}

Mills, C 2014, 'Introduction', in C Mills (ed), Ethics and Children's Literature, Ashgate, Aldershot, pp. 1-12.

\section{Biographical Note}

Kristine Moruzi is a lecturer and ARC Discovery Early Career Researcher in the School of Communication and Creative Arts at Deakin University. Her monograph, Constructing Girlhood through the Periodical Press, 1850-1915 was published by Ashgate in 2012. She is the co-editor of the six-volume anthology Girls' School Stories, 1749-1929 (Routledge 2013), Colonial Girlhood in Literature, Culture and History, 1840-1950 (Palgrave 2014), and Affect, Emotion, and Children's Literature: Representation and Socialisation in Texts for Children and Young Adults (Routledge, forthcoming). Her current project is on The Charitable Child: Children and Philanthropy in the Nineteenth and Early Twentieth Centuries. 